Basu, S. N. (1951). J. gen. Microbiol. 5, 231-238.

\title{
Significance of Calcium in the Fruiting of Chaetomium Species, Particularly Chaetomium globosum
}

\author{
By S. N. BASU \\ The Microbiology Department, Indian Jute Mills Association Research \\ Institute, Calcutta
}

SUMMARY: Calcium is required by Chaetomium globosum for the normal formation of perithecia, but is not essential for vegetative growth. Calcium is at least partly replaceable by strontium or barium. Most of the other species of Chaetomium tested responded to calcium, either in fruiting or growth, or both.

Suitable doses of calcium reproduce in a large measure the previously observed effect of jute extract on the fruiting of Chaetomium species. The presence of calcium in jute extract was established.

It has been observed previously that growth and perithecial formation of Chaetomium globosum are markedly stimulated by a hot-water extract of jute fibre (Buston \& Basu, 1948), and that the ash of this extract also has a somewhat similar effect on this and other species of Chaetomium (Basu \& Bose, 1950). The specific nature of the factors responsible was not established. Further investigation, embodied in the present paper, shows that calcium, which is present in jute extract, stimulates the fruiting of $C$. globosum. Light has also been thrown on the effect of some other trace metals on this fungus, and of calcium on the growth and fruiting of a few other Chaetomium species.

\section{MATERIALS AND METHODS}

Three strains of $C$. globosum Kunze, all isolated in this laboratory, were used in these studies; no. 79, the strain used in our previous investigations, and no. $79 \cdot 2$, were isolations from perithecial growths on paper, and no. $79 \cdot 1$ was from a plating of fresh jute fabric. Stock cultures of these were preserved on malt agar slants in the refrigerator.

The medium used was Czapek's salt solution (with $\mathrm{K}_{2} \mathrm{HPO}_{4}$ and without $\mathrm{Fe}$ ) and $0.2 \%$ glucose $(\mathrm{w} / \mathrm{v}) ; \mathrm{pH}$ was $7 \cdot 4$. Ten $\mathrm{ml}$. quantities were distributed into $125 \mathrm{ml}$. American made (see below, p. 236) Pyrex conical flasks (cleaned before each test with hot chromic-sulphuric acid) and sterilized at $10 \mathrm{lb}$. for $10 \mathrm{~min}$. Each flask was inoculated with a loopful of spore suspension prepared by crushing a few perithecia in a drop of sterile distilled water. Incubation was at $27^{\circ}$ for 20 days.

Structures representing the first beginning of perithecia formation and only just visible as small specks on the mycelium were recorded as immature perithecia. The appearance of ascospores was detected by microscopical examination of crushed perithecia. Counting of perithecia was often difficult and probably not very accurate when the number was very large or when they tended to adhere in thick clusters. Size of perithecia was computed by eye; perithecia reported as 'large' had the dimensions demanded by the species description; 
however, smaller but mature perithecia were always indistinguishable from these except in size.

Usually duplicate flasks were used and both results are reported; lack of resources did not always permit use of flasks in pairs, but the positive results reported have been checked by repeated experiments. Though replications did not always yield the same figures and sometimes showed considerable divergences, results have not been considered valid unless the same relative values were obtained.

\section{RESULTS}

Strain 79 formed perithecia even when the initial glucose concentration was $0.01 \%(w / v)$, although their number was limited by the small amount of growth; at $0 \cdot 1 \%(w / v)$ glucose a few small but mature perithecia were formed, but at $\mathbf{0 . 2} \%(\mathrm{w} / \mathrm{v})$ glucose only a number of immature perithecia, seldom forming spores in any numbers although often possessing long and characteristically curved terminal hairs, were to be seen.

\section{Effect of calcium}

The effect of $\mathrm{Ca}\left(\mathrm{as} \mathrm{CaCl}_{2}\right)$ over a wide range of concentrations is shown in Table 1. At the two highest concentrations there was some turbidity in the medium when first prepared due to the precipitation of Ca salts, but this soon disappeared in the course of growth. With each strain the best all-round effect on fruiting was obtained at 10 p.p.m. Ca. The effect disappeared at $0 \cdot 1$ p.p.m. The inhibitory action of comparatively high Ca concentrations was manifested, apart from the results recorded in Table 1 , in the incomplete growth of strain no. 79 at 1000 p.p.m. and in the texture of the mycelia of strains nos. $79 \cdot 1$ and $79 \cdot 2$ which formed small detached colonies instead of the normal mat. It was also noticed that as the $\mathrm{Ca}$ concentration reached 10 p.p.m. perithecia tended to adhere in clusters, their size was more uniform, and there were few immature perithecia left. The proportion of immature perithecia increased particularly with the lowering of $\mathrm{Ca}$ concentration. Freedom of perithecial formation was noticeably higher in strain no. 79.1 than in the other two strains. Strain no. 79 displayed the sharpest responses to $\mathrm{Ca}$ so that this strain was used in more experiments than the others.

The optimum $\mathrm{Ca}$ requirement was more accurately determined within a narrower range of concentrations and was found to be near 10 p.p.m. for all strains. The results obtained with strain no. 79 are given in Table 2 . It may be noted that perithecial number and size of strain no. 79 at 10 p.p.m. Ca level are different in Tables 1 and 2. The same tendency, namely that of an increase in number at the expense of size, or vice versa, was observed, within limits, in several other instances.

\section{Other trace metals}

The presence of $\mathrm{Ca}$ in jute extract was established by a microchemical test using a saturated solution of picrolonic acid which gave rectangular crystals characteristic of Ca. A spectrographic analysis of the ash of jute extract was kindly made for us by Prof. P. B. Sarkar of the Calcutta University and, besides 
Table 1. Effects of different concentrations of calcium on three strains of Chaetomium globosum

Day of

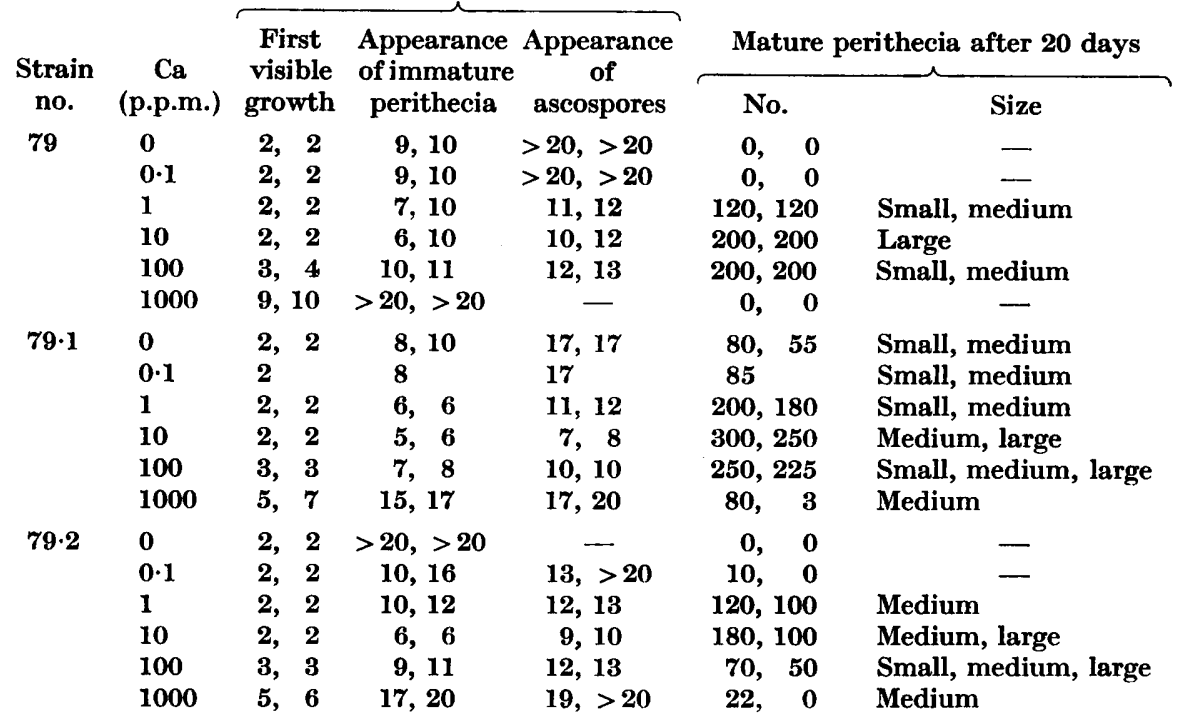

Table 2. Optimum calcium concentration for Chaetomium globosum strain 79

$\begin{array}{ccccc}\text { Ca (p.p.m.) } & \overbrace{\begin{array}{c}\text { Immature } \\ \text { perithecia }\end{array}}^{\text {Day of appearance of }} & \text { Ascospores } & \overbrace{\text { No. }}^{\text {Mature perithecia after 20 days }} \\ 0 & 7 & >20 & 0 & \text { Size } \\ 1 & 5 & 8 & 90 & \text { Small } \\ 5 & 5 & 7 & 150 & \text { Medium } \\ 6 \cdot 7 & 5 & 7 & 300 & \text { Medium } \\ 10 & 5 & 7 & 330 & \text { Medium } \\ 20 & 6 & 7 & 160 & \text { Medium } \\ 100 & 10 & 12 & 120 & \text { Small }\end{array}$

Table 3. Comparative effects of some other metals on Chaetomium globosum strain 79

Day of appearance of

\begin{tabular}{|c|c|c|c|c|c|}
\hline \multirow[b]{2}{*}{ Metal } & \multirow[b]{2}{*}{$\begin{array}{l}\text { Concn. } \\
\text { (p.p.m.) }\end{array}$} & \multicolumn{2}{|c|}{ Day of appearance of } & \multicolumn{2}{|c|}{ Mature perithecia after 20 days } \\
\hline & & $\begin{array}{l}\text { Immature } \\
\text { perithecia }\end{array}$ & Ascospores & No. & Size \\
\hline $\mathbf{B a}$ & $\begin{array}{r}10 \\
1\end{array}$ & $\begin{array}{l}5,6 \\
6\end{array}$ & $\begin{array}{l}8,9 \\
9\end{array}$ & $\begin{aligned} 110, & 90 \\
60 & \end{aligned}$ & $\begin{array}{l}\text { Medium, large } \\
\text { Small, medium }\end{array}$ \\
\hline $\mathrm{Sr}$ & $\begin{array}{r}10 \\
1\end{array}$ & $\begin{array}{l}6,6 \\
6\end{array}$ & $\begin{array}{l}8,9 \\
9\end{array}$ & $\begin{array}{l}250,170 \\
40\end{array}$ & $\begin{array}{l}\text { Medium, large } \\
\text { Small }\end{array}$ \\
\hline Mn & $\begin{array}{r}10 \\
1\end{array}$ & $\begin{array}{l}6,6 \\
6\end{array}$ & $\begin{array}{l}10,10 \\
10,11\end{array}$ & $\begin{array}{ll}\text { 30, } & 20 \\
\mathbf{3 0} & \end{array}$ & $\begin{array}{l}\text { Minute } \\
\text { Small }\end{array}$ \\
\hline $\mathrm{Ca}$ & $\begin{array}{r}10 \\
1\end{array}$ & $\begin{array}{l}5,5 \\
5\end{array}$ & $\begin{array}{l}8,9 \\
9\end{array}$ & $\begin{array}{l}300,200 \\
120\end{array}$ & $\begin{array}{l}\text { Medium, large } \\
\text { Small, medium }\end{array}$ \\
\hline
\end{tabular}


confirming the presence of $\mathrm{Ca}$, it indicated the occurrence of $\mathrm{Mg}, \mathrm{Fe}, \mathrm{Co}, \mathrm{Sn}$, $\mathrm{Ni}, \mathbf{M n}, \mathbf{P b}, \mathrm{Si}$ and $\mathbf{P}$ in the ash. Since $\mathbf{M g}$ and $\mathbf{P}$ were present in the basal medium, only the other elements (with the exception of Si) were tested, mostly at 10 and 1 p.p.m. levels, with strain no. 79. No positive effect was noticed except a small one with Mn, already mentioned (Basu \& Bose, 1950). Co and $\mathrm{Ni}$ had inhibitory action on vegetative growth. $\mathrm{Mg}$ in the medium could not be replaced by $\mathrm{Ca}$; without $\mathrm{Mg}$, growth was small and there was no fruiting even in the presence of $\mathrm{Ca}$ which only slightly increased growth. Ca was found to be replaceable, at least partly, by $\mathrm{Ba}$ and $\mathrm{Sr}$. These elements and $\mathrm{Mn}$ are compared with $\mathrm{Ca}$ in Table 3. The salts used were $\mathrm{BaCl}_{2}, \operatorname{Sr}\left(\mathrm{NO}_{3}\right)_{2}$ and $\mathrm{MnSO}_{4} .4 \mathrm{H}_{2} \mathrm{O}$, recrystallized before use. In other experiments $\mathrm{Ba}$ and $\mathrm{Sr}$ at high concentrations exhibited the same inhibitory effect as observed with $\mathrm{Ca}$. The perithecial number given by $\mathrm{Ba}$ was never as high as that obtained at optimum $\mathrm{Ca}$ concentration. $\mathrm{Ba}$ and $\mathrm{Sr}$ had about the same optimum concentration as $\mathrm{Ca}$, but $\mathrm{Mn}$ showed the best effect at $c .1$ p.p.m. Even at this concentration the perithecial number and size were never comparable with those in presence of $\mathrm{Ca}$, although the small perithecia given became mature and developed spores. When Ca was combined with one, two or three of the other metals at optimum concentrations no superiority over $\mathrm{Ca}$ alone was observed.

Table 4. Effects of jute extract on the three strains, and comparative effects of jute extract, its ash, and calcium on strain 79 of Chaetomium globosum

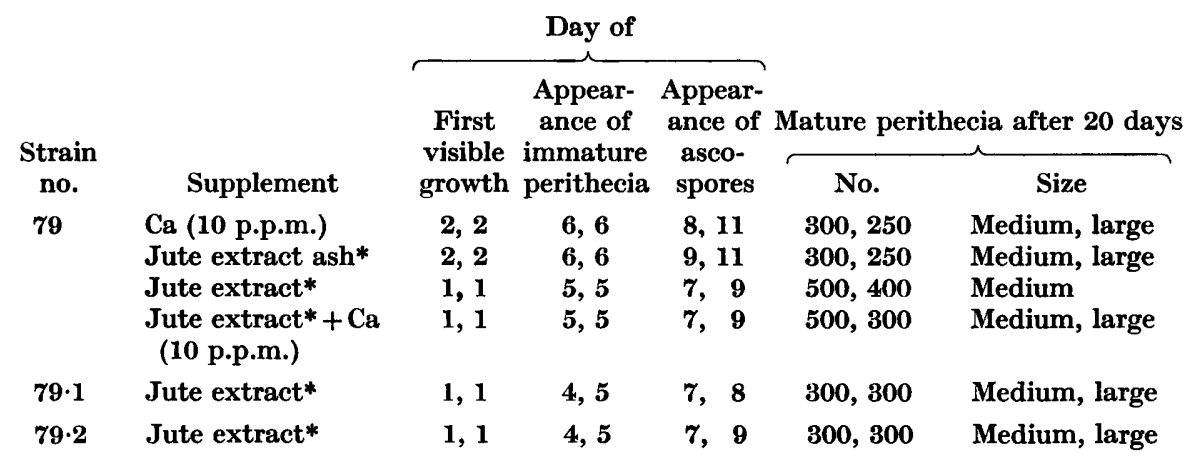

* Concentration of jute extract was equivalent to $3.5 \mathrm{~g}$. jute fibre/100 ml. of final medium.

\section{Comparison with jute extract}

Combinations of $\mathrm{Ca}$ with biotin, aneurin, riboflavin, pyridoxin, nicotinic acid or pantothenic acid (all present in jute extract; Buston \& Basu, 1948), at $1,0 \cdot 1,0.01 \mu \mathrm{g}$. of each vitamin per flask also did not yield better results. The effect of $\mathrm{Ca}$ on fruiting, though somewhat different from that of jute extract, was nearly the same as the effect of the ash of this extract at the concentration tried (Table 4). Stimulation of germination and growth by jute extract was evident in all three strains, and jute extract also gave an appreciably higher number of perithecia than $\mathrm{Ca}$ in strains nos.79 and 79.2. However, in the case of strain no. 79 the perithecial size generally obtained with jute extract did not appear to be quite up to normal size. This was confirmed by 
measurement of a large number of perithecia from several different sets of experiments. Perithecia obtained in presence of $\mathrm{Ca}$ usually exceeded $200 \mu$. in length, whereas those given by jute extract rarely did so. This is another example of the balance between perithecial number and size as observed above.

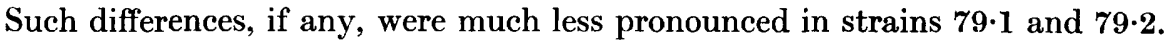

\section{Comparison of growth and fruiting effects}

Ca stimulated fruiting in two strains even when added to stale medium long after vegetative growth had ceased and autolysis had set in (Table 5). The absence of response by strain no. $79 \cdot 2$ may be connected with the absence of immature perithecia before the addition of Ca (Table 1). The number of perithecia produced by strain no. 79 was smaller than when Ca was added before growth, probably due to the presence of products of staling and autolysis. However these results indicated that fruiting could be stimulated independently of vegetative growth. The same conclusion is suggested also by the effect of jute extract.

Table 5. Effects on the fruiting of the three strains of Chaetomium globosum of supplements added after completion of growth

Ca added at 10 p.p.m. where used.

\begin{tabular}{|c|c|c|c|c|c|}
\hline \multirow[b]{2}{*}{$\begin{array}{l}\text { Strain } \\
\text { no. }\end{array}$} & \multicolumn{2}{|c|}{ Mature perithecia after 20 days } & \multirow{2}{*}{$\begin{array}{l}\text { Supplement added } \\
\text { after } 20 \text { days }\end{array}$} & \multicolumn{2}{|c|}{$\begin{array}{l}\text { Mature perithecia after } \\
\text { 40 days }\end{array}$} \\
\hline & No. & Size & & No. & Size \\
\hline 79 & $0, \quad 0$ & - & Ca & 120,60 & Medium \\
\hline $\begin{array}{l}79 \\
79 \cdot 1\end{array}$ & $\begin{array}{r}4 \\
80,55\end{array}$ & $\begin{array}{l}\text { Small } \\
\text { Small to medium }\end{array}$ & $\begin{array}{l}\text { Jute extract* } \\
\text { Ca }\end{array}$ & $\begin{array}{l}120 \\
300,300\end{array}$ & $\begin{array}{l}\text { Medium } \\
\text { Medium }\end{array}$ \\
\hline $79 \cdot 2$ & $\mathbf{0}, \quad \mathbf{0}$ & - & $\mathrm{Ca}$ & $\mathbf{0}$, & - \\
\hline
\end{tabular}

The effects of jute extract and $\mathrm{Ca}$ on vegetative growth were compared with growth on the basal medium by progressive measurement of mycelium weights till growth had reached the maximum. Fig. 1 shows that $\mathrm{Ca}$ had no significant effect on growth although jute extract increased both rate of growth and the maximum mycelium weight reached. Since growth on jute extract alone in distilled water was negligible (although some mature perithecia were formed), the increased mycelium weight given by jute extract + basal medium cannot be explained by the presence of additional carbon sources in the extract. That Ca did not have any perceptible influence on germination, rate of growth or cell synthesis efficiency was confirmed in another experiment in which both increase in mycelium weight and disappearance of glucose in the medium was progressively followed with and without 10 p.p.m. Ca in the medium; in this experiment the $\mathrm{pH}$ reached $\mathbf{9 \cdot 5}$ shortly after growth started in both media and remained more or less stationary there. 


\section{Effect of calcium on other species}

The effect of $\mathrm{Ca}$ at 10 p.p.m. concentration was tried on several other species of Chaetomium. The results are given in Table 6 , where instances of stimulation of germination, of ultimate growth and of fruiting are seen. C. microcephalum Ames (no. 113) and C. pachypodioides Ames (no. 114), which were also tested, did not germinate even in the presence of $\mathrm{Ca}$. It should be noted that only those species in which fruiting is stimulated by $\mathrm{Ca}$ had previously shown a similar response to jute extract or its ash (Basu \& Bose, 1950).

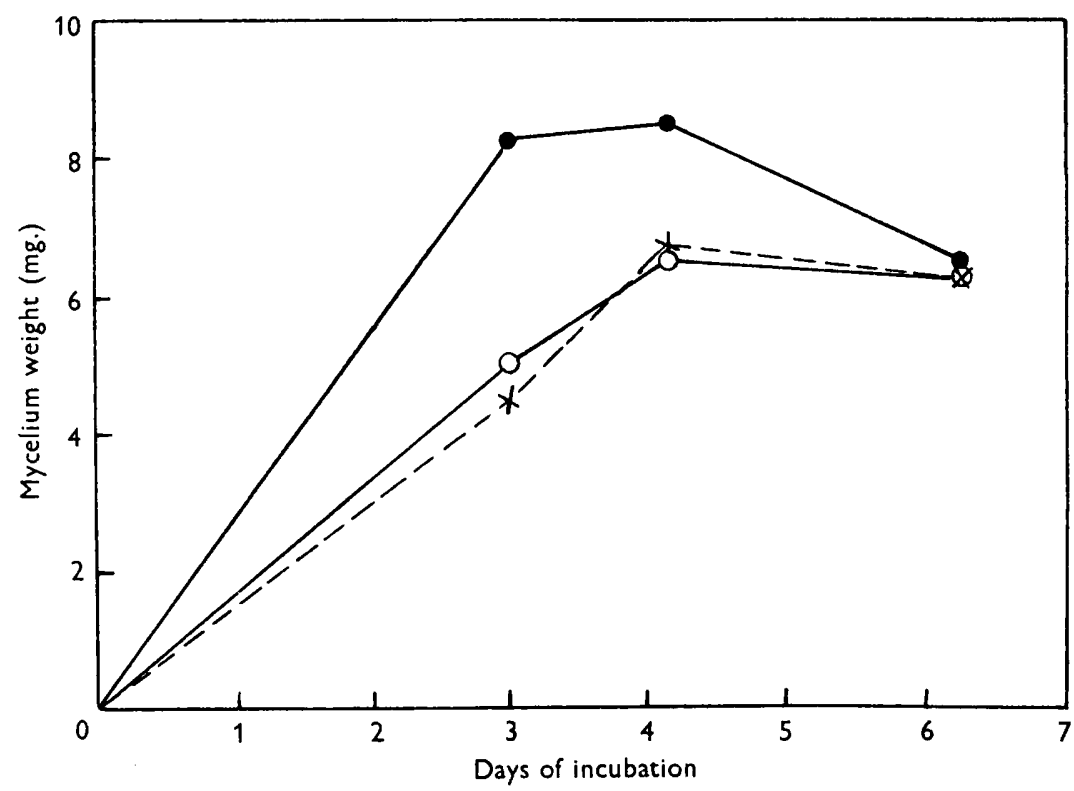

Fig. 1. Effect of calcium and jute extract on the growth of Chaetomium globosum strain no. 79. $\times \cdots \times$, on basal medium; $\bigcirc-O$, on basal medium with 6.5 p.p.m. calcium; - on basal medium with jute extract (concentration as in Table 4).

\section{Effect of glassware}

Apart from the evidence reported above, there were other indications that C. globosum was very sensitive to minute traces of mineral elements. Erratic results were obtained when flasks other than Pyrex were used; thus, Monax flasks gave abnormal growth in the form of small isolated colonies of the type caused, for example, by traces of $\mathrm{Zn}$ or high doses of $\mathrm{Ca}$ in the medium. Two Indian-made glasses resulted in different types of abnormal growth and stimulated fruiting. Even Pyrex flasks made in England were somewhat more favourable for fruiting than the American-made flasks used in these experiments. All this suggested that in a purer basal medium, fruiting might in general be further suppressed. However, when strain no. 79 was grown on a medium made with twice-recrystallized salts and with water twice distilled in a Pyrex glass apparatus the same type of mycelium showing immature perithecia was obtained. When the basal medium was made up with $\mathrm{KH}_{2} \mathrm{PO}_{4}$ 
Table 6. Effects of calcium on the growth and fruiting of several species of Chaetomium

\begin{tabular}{|c|c|c|c|c|c|c|c|}
\hline \multirow{2}{*}{$\begin{array}{c}\text { Reference } \\
\text { no. of } \\
\text { organism }\end{array}$} & \multicolumn{3}{|c|}{$\begin{array}{c}\begin{array}{c}\text { Day of first } \\
\text { visible } \\
\text { growth }\end{array} \\
\text {. }\end{array}$} & \multicolumn{2}{|c|}{ Final growth* } & \multicolumn{2}{|c|}{ Final fruiting* } \\
\hline & Species & $\begin{array}{l}\text { No } \\
\text { Ca }\end{array}$ & $+\mathrm{Ca}$ & No Ca & $+\mathbf{C a}$ & $\begin{array}{l}\text { No } \\
\text { Ca }\end{array}$ & $+\mathrm{Ca}$ \\
\hline 75 & C. indicum Corda & $\mathbf{5}$ & 5 & +++ & +++ & $\mathbf{0}$ & $++t$ \\
\hline 108 & C. cancroideum Tschudy & $\mathbf{5}$ & 4 & + & $++t$ & $\mathbf{0}$ & 0 \\
\hline 109 & C. ochraceum Tschudy & 3 & 3 & + & $++t$ & $\mathbf{0}$ & $\mathbf{0}$ \\
\hline 110 & C. cochliodes Palliser & $\mathbf{3}$ & 3 & ++ & ++ & o & +++ \\
\hline 111 & C. dolichotrichum Ames & 2 & 1 & ++ & +++ & $\mathbf{0}$ & +++ \\
\hline 112 & C. funicola Cooke & 6 & 3 & + & ++ & $\mathbf{0}$ & ++ \\
\hline 115 & Chaetomium sp. & $\mathbf{5}$ & 2 & + & +++ & $\mathbf{0}$ & 0 \\
\hline 116 & C. elatum Kunze \& Schm. & 4 & 4 & + & ++ & 0 & 0 \\
\hline
\end{tabular}

* Increasing number of + signs denotes increasing amounts of growth or fruiting. Zero indicates no fruiting.

instead of $\mathrm{K}_{2} \mathrm{HPO}_{4}$ the initial pH was $5 \cdot 0$ and growth was rather slow and in the form of small separate colonies, although ultimately a few small but mature perithecia developed. Some evidence was also obtained that on a solid medium (malt agar), artificial light stimulated colony growth of strain no. 79 but retarded the development of perithecia, which also formed abnormal straight hairs. A thicker depth of medium gave more perithecia, within certain limits.

\section{DISCUSSION}

Specific instances of stimulation of growth or sporulation of micro-organisms by calcium are meagre in the literature, and there does not seem to be any known instance of the stimulation of the sexual cycle of a fungus by a trace element. Steinberg (1948) found that calcium increased the vegetative growth of several fungi of which Rhizoctonia solani showed the most marked response, growth without calcium being only $14.3 \%$ of that with calcium. Discussing the fact that calcium is not known to be required by other fungi, Steinberg has raised the point that with the attainment of greater levels of purity in the basal medium, greater uniformity in the requirement of trace elements by fungi may be found. It is possible that in the experiments here reported some calcium was present as impurity in the basal medium in spite of efforts at purification. Glucose and glassware have been known to contribute calcium (Foster, 1949), and $C$. globosum is clearly sensitive to the kind of glassware; calcium may also have come from the cotton plug or the inoculum. It is therefore possible that the use of a medium more stringently freed from calcium would reveal a calcium requirement for vegetative growth. Some support is lent to this possibility by the fact that calcium stimulates the growth of some other species of Chaetomium.

Apart from this reservation, calcium seems to have an effect only on the fruiting mechanism of $\boldsymbol{C}$. globosum as distinct from growth; such instances are at present rare. In the case of fungi, most trace-element work has been 
confined to species, like Aspergillus niger, which do not form the perfect stage, and although the formation of asexual spores is known to be affected in some cases, the effect of trace elements has so far been observed primarily on vegetative growth. Foster \& Heiligman (1949) reported that potassium ions (and probably also magnesium and iron) are required for the spore formation of some species of the bacterial genus Bacillus, and that the effect is independent of vegetative growth. This is comparable with the action of calcium on Chaetomium globosum, although the genetical mechanism of spore formation in the two instances may be very dissimilar.

Inhibition of fruiting, and ultimately of growth, by relatively high concentrations of calcium is comparable with similar effects of growth factors, organic and inorganic, observed by other workers. Calcium is known to be an activator of some enzymes (Foster, 1949); in the case of $C$. globosum it may form part of an enzyme system where it is largely replaceable by strontium or barium. Steinberg (1948) also found calcium partially replaceable by strontium, though not by barium, in the case of Rhizoctonia solani. It should be interesting to investigate in what way such an enzyme influences the fruiting of Chaetomium globosum without apparently taking part in the purely growth processes, and also to study the nature of the organic factor present in jute extract which, owing to its stimulating action on germination and growth, exerts at least an indirect effect on the fruiting of the species.

Thanks are due to the Research Director, Indian Jute Mills Association Research Institute, for permission to publish these results.

\section{REFERENCES}

Basu, S. N. \& Bose, R. G. (1950). Factors affecting the fruiting of Chaetomium species. J. gen. Microbiol. 4, 132.

Buston, H. W. \& BAsu, S. N. (1948). Some factors affecting the growth and sporulation of Chaetomium globosum and Memnoniella echinata. J. gen. Microbiol. 2, 162.

Foster, J. W. (1949). Chemical Activities of Fungi, 1st ed. New York: Academic Press Inc.

Foster, J. W. \& Heiligman, F. (1949). Mineral deficiencies in complex organic media as limiting factors in the sporulation of aerobic bacilli. J. Bact. 57, 613 .

Steingerg, R. A. (1948). Essentiality of calcium in the nutrition of fungi. Science, 107, 423. 